\title{
Influenced of Twill Geometry Variation on Woven Fabrics: Analysis of Physico-Chemical Properties
}

\author{
Solaiman ${ }^{1}$, Hemonta Kumar Sarkar ${ }^{2}$, Sefayet Ullah², Jannatul Bake Molla3, \\ Abul Kasem Mohammed Fazlul Haque ${ }^{1}$ \\ ${ }^{1}$ Textile Engineering College, Noakhali, Bangladesh University of Textiles, Dhaka, Bangladesh \\ ${ }^{2}$ Department of Fabric Manufacturing Engineering, Textile Engineering College, Noakhali, Bangladesh University of Textiles, \\ Dhaka, Bangladesh \\ ${ }^{3}$ Bangladesh Jute Research Institute, Dhaka, Bangladesh \\ Email: *solaimanbari@gmail.com, sarkarhemonta776@gmail.com, tu sharicetecn@gmail.com,parvez31tex@gmail.com, \\ akmfazlulhaque1@gmail.com
}

How to cite this paper: Solaiman, Sarkar, H.K., Ullah, S., Molla, J.B. and Haque, A.K.M.F. (2019) Influenced of Twill Geometry Variation on Woven Fabrics: Analysis of Physico-Chemical Properties. Journal of Textile Science and Technology, 5, 134-147. https://doi.org/10.4236/jtst.2019.54012

Received: September 18, 2019

Accepted: November 24, 2019

Published: November 27, 2019

Copyright $\odot 2019$ by author(s) and Scientific Research Publishing Inc. This work is licensed under the Creative Commons Attribution International License (CC BY 4.0).

http://creativecommons.org/licenses/by/4.0/

\begin{abstract}
It has been analyzed the properties such as tensile strength, tearing resistance, crease angle recovery, pilling formation, drape co-efficient, colorfastness to rubbing and colorfastness wash by testing with the help of related instrument, The twill woven fabrics which are chosen only different to their weave structure (2/1 S twill and 3/1 S twill) whether the other specification of the fabrics like warp count, weft count, ends per inch, picks per inch, GSM of the fabrics and the fiber quality were same. From the experiment, it was found that some properties such as tensile strength, drape co-efficient and colorfastness of $2 / 1$ twill are better than $3 / 1$ twill on the other hand few properties such as crease angle recovery, tearing resistance and colorfastness to wash of $3 / 1$ twill is better than $2 / 1$ twill. Afterward while performing the job for identifying the pill formation tendency, it was observed that pill formation tendencies of the both fabrics are same.
\end{abstract}

\section{Keywords}

Twill Fabrics, Reactive Dyes, Tensile Strength, Tearing Resistance,

Color Fastness to Rubbing

\section{Introduction}

Fabric is such a construction used by human being. The term "fabric" is originated from French "fabrique". There are different methods to produce fabric 
such as weaving, knitting, non-woven, etc. According to their manufacturing method the fabric is called woven fabric, knit fabric, and non-woven fabric respectively. Nowadays woven fabrics become more and more popular and highly needable fabric. This fabric is used for producing casual shirts, pants, household purposes, technical purposes, etc. [1]. Different properties of fabric are needed for different purposes. According to the latest consumption we can easily see that about three billion meters of woven fabric is required for export every year but we can export only about forty-five million meters of woven fabric. This consumption easily showed the lacking of our woven fabric industry. We have to set up more and more woven fabric industry and increase their productivity, because there is a huge gap between supply and demand of woven fabric. On the other hand the demand for fabric is increasing day by day gradually [2]. So it is more and more important to increase woven industry and their productivity.

Besides, the production and product quality also have to be increased because without improving product and production quality we could not catch the foreign market. The quality of product depends largely upon the constructional parameters of the fabric which is determined by the weave thread density, weave structure, characteristics of warp and weft threads, characteristics of fiber, etc. [3]. Among the above constructional parameters we have chosen the weave structure of woven fabric to identify the variety of fabric properties. As the properties of fabric vary according to their weave structure, we have taken two twill structure of woven fabric such as $2 / 1 \mathrm{~S}$ twill and $3 / 1 \mathrm{~S}$ twill to determine the "Influenced of Different Twill Geometry in Woven Fabrics: Analysis of Physico-Chemical Properties" [4].

There are two particular interlacing types for making the woven fabric such as "warp over the weft" and "weft over the warp". The fabric is formed according to the demand. Different combinations can form short and long floats of warp and weft threads and can form infinite variety of weave. Since the properties of woven fabric are greatly depends upon the weave structure, we have to choose the better one for making fabric. This experiment will show us which twill weave structures of woven fabric are more appropriate for making high quality woven fabric for the specific purposes [5].

\section{Experimental}

Two samples of $100 \%$ cotton twill grey fabrics are collected from the Gulsan Ara City, Islampur, Dhaka. After collecting, the fabrics are analysed very carefully. The GSM of the both fabrics are 190, the warp yarn count and the weft yarn count of the both samples are $30 \mathrm{~s}$ and $20 \mathrm{~s}$ respectively. The structure of the samples are 2/1 Z twill and 3/1 Z twill. The cloth cover factors of the both samples are 32.59 and 28.97 respectively. The ends per inch and the picks per inch for $2 / 1 \mathrm{Z}$ twill sample are 123 and 71 respectively and for $3 / 1 \mathrm{Z}$ twill sample are 127 and 69 respectively. These fabrics are collected for determining the effect of twill structure on physico-chemical properties on woven fabric. 


\subsection{Methods of Dyeing Process of Twill Fabric}

\subsubsection{Desizing Procedure of Twill Fabrics}

For desizing process $617 \mathrm{gm}$ and $568 \mathrm{gm}$ samples were taken for $2 / 1 \mathrm{Z}$ twill and $3 / 1 \mathrm{Z}$ twill respectively. The total weight of the two fabrics was $1185 \mathrm{gm}$. The water was taken inside the machine according to the liquor ratio 1:8 (required amount of water is $9.5 \mathrm{~L}$ ). Then Acetic acid was taken $47.5 \mathrm{ml}$ considering acetic acid ratio $5 \mathrm{ml} / \mathrm{L}$. After that, samples were given into the machine and run at normal temperature for 30 minutes [4].

\subsubsection{Soaping and Normal Wash Procedure}

After completing the desizing process, drain out the water and took $20 \mathrm{~L}$ water in the machine for soaping wash. $40 \mathrm{ml}$ soaping agent (on the basis of $2 \mathrm{gm} / \mathrm{l}$ ) was taken into the machine and ran the machine at normal temperature for 10 minutes, then done the normal wash for 10 minutes. Finally excess water was removed from the samples by Hydro-extractor machine at rpm of 1100 for 5 minutes [4].

\subsubsection{Scouring and Bleaching Procedure for the Twill Fabrics}

For the scouring and bleaching process (Figure 1), $20 \mathrm{~L}$ water was taken into the machine. Then amount of recipe calculated for essential chemicals. After calculating it was found that Alkali $(\mathrm{NaOH})$ amount was $100 \mathrm{gm}$. (considering $5 \mathrm{gm} / \mathrm{l}$ ), Soda ash amount was $40 \mathrm{gm}$. (considering $2 \mathrm{gm} / \mathrm{l}$ ), Wetting agent amount was 20 $\mathrm{ml}$ (considering $1 \mathrm{ml} / \mathrm{l}$ ), Levelling agent amount was $20 \mathrm{ml}$ (considering $1 \mathrm{ml} / \mathrm{l}$ ), Sequestering agent amount was $10 \mathrm{ml}$ (considering $0.5 \mathrm{ml} / \mathrm{l}$ ), Stabilizer amount was $20 \mathrm{gm}$. (considering $1 \mathrm{gm} / \mathrm{l}$ ), Bleaching powder amount was $120 \mathrm{gm}$. (considering $6 \mathrm{gm} / \mathrm{l})$. After took all necessary chemicals and sample in the machine, temperature raised up to $98^{\circ} \mathrm{C}$ and ran for 60 minutes at this temperature. Then drain out the water and took new water for hot wash. Hot wash was conducted at $95^{\circ} \mathrm{C}$ temperature for 10 minutes. After that cold wash was done for 5 minutes [4].

\subsubsection{Per-Oxide Killer}

Per-oxide killer was used for inactive the per-oxide agent. For this process $20 \mathrm{~L}$ water was taken into the machine and then $20 \mathrm{ml}$ (considering $1 \mathrm{ml} / \mathrm{l}$ ) per-oxide

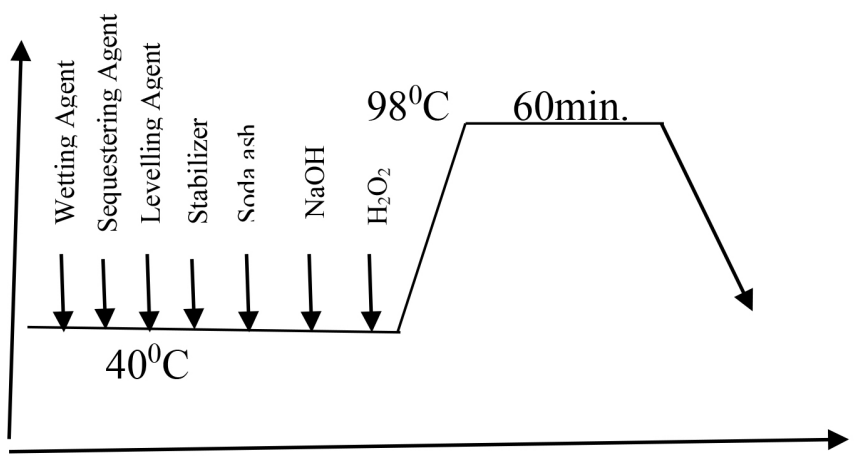

Figure 1. Graphical representation of scouring and bleaching procedure. 
killer was taken. Then the temperature was raised up to $75^{\circ} \mathrm{C}$ within 15 minutes and ran the process for 10 minutes. After that drain out the water and took new water for the next process [4].

\subsubsection{Neutralization}

In a reaction in water, neutralization results in there being no excess of hydrogen or hydro-oxide ions present in the solution. The $\mathrm{pH}$ of the neutralized solution depends on the acid strength of the reactants. For neutralization $(20 \mathrm{ml})$ Acetic acid (considering $1 \mathrm{ml} / \mathrm{l}$ ) was taken in $20 \mathrm{~L}$ water and ran the machine for 10 minutes at normal temperature. After completing the process drain out the water and took new water for cold wash which was done for 5 minutes. Finally, removed the excess water from the samples by Hydro-extractor at $1100 \mathrm{rpm}$ within 5 minutes and dried the samples at $30^{\circ} \mathrm{C}-40^{\circ} \mathrm{C}$ temperature for $1 \mathrm{hr} 30$ $\min [4]$.

\subsubsection{Dyeing Process of the Twill Fabric}

Dyeing is the application of dyes on textile materials with the goals of achieving color with desired color fastness. Dyeing is normally done in a special solution containing dyes and particular chemical materials. In this experiment (Figure 2 ), the total weight of the samples which was $556 \mathrm{gm} .23 \mathrm{~L}$ water was taken considering the liquor ratio 1:40 then add the required quantity of dyes and chemicals into the machine. The required quantity of dyes and chemicals were wetting agent $23 \mathrm{ml}$ (considering $1 \mathrm{ml} / \mathrm{l}$ ), sequestering agent $11.5 \mathrm{ml}$ (considering 0.0 $\mathrm{ml} / \mathrm{l}$ ), levelling agent $23 \mathrm{ml}$ (considering $1 \mathrm{ml} / \mathrm{l}$ ), stabilizer $23 \mathrm{gm}$ (considering 1 $\mathrm{gm} / \mathrm{l}$ ), gluaber salt $40 \mathrm{~g} / \mathrm{l}$ and soda ash $15 \mathrm{gm} / \mathrm{l}$ (according to the shade \%, here shade \% is 3.5). So the calculated gluaber salt was $900 \mathrm{gm}$. soda ash was $345 \mathrm{gm}$. After taking the chemicals the samples were added to the dye bath then the dyes were dossing at $60^{\circ} \mathrm{C}$ temperature at 20 minutes. Two reactive dyes were used such as Red was $34.5 \mathrm{gm}$ (considering $1.5 \mathrm{gm} / \mathrm{l}$ ) and Blue was $46 \mathrm{gm}$ (considering $2 \mathrm{gm} / \mathrm{l}$ ). After dossing the dyes, temperature was raised up to $80^{\circ} \mathrm{C}$ and then soda was dossing into the dye bath at $80^{\circ} \mathrm{C}$ temperature for 10 minutes; then ran the machine at $80^{\circ} \mathrm{C}$ for 45 minutes. Finally, drain out the water and take new water [4].

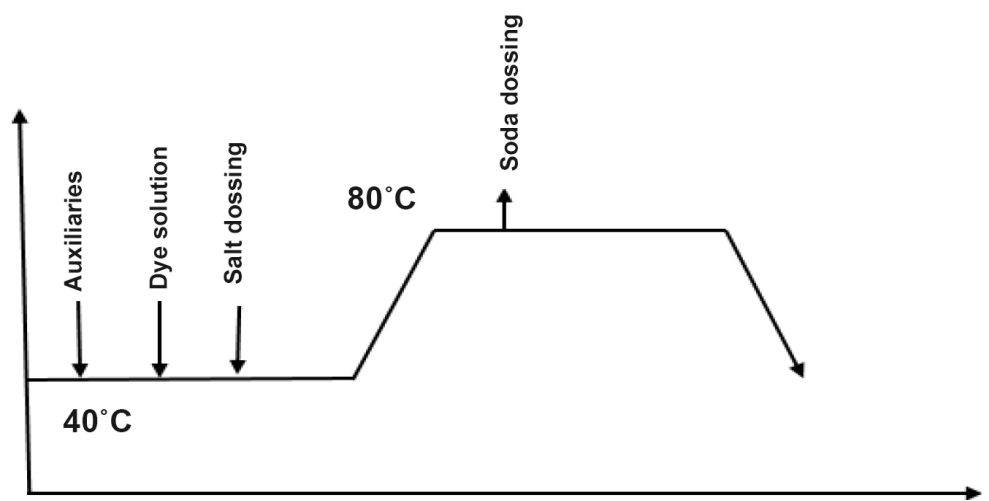

Figure 2. Graphical representation of dyeing procedure. 


\subsubsection{After Treatment Process}

For the after treatment process took soda $46 \mathrm{gm}$ (considering $2 \mathrm{gm} / \mathrm{l}$ ) and soaping agent $23 \mathrm{ml}$ (considering $1 \mathrm{ml} / \mathrm{l}$ ) then ran the machine at $60^{\circ} \mathrm{C}$ temperature for 10 minutes. After completing the process wash the samples for 5 minutes by normal water then completing hot wash at $95^{\circ} \mathrm{C}$ at 10 minutes. After that cooled the samples and removed the excess water by Hydro-extractor at $1100 \mathrm{rpm}$ for 5 minutes and finally dry the samples at $400 \mathrm{C}$ temperature for $1 \mathrm{hr}$ and 30 minutes [4].

\section{Methods of Testing of Twill Fabric}

\subsection{Testing Procedure of Tensile Strength (ISO 13934-1)}

The tensile strength is the measure of maximum force that fabric can bear or support, elongate before it breaks. For determining tensile strength ISO 13934-1 test methods mentioned the strip test. The specimen used in this test is usually a 2 inch wide piece of fabric prepared by initially cutting the material to a width of about 2.5 inch and removing threads from both edges until the width has been reduced to 2 inch. The test length should be 8 inch between the jaws and so enough extra length must be allowed for gripping in the jaws. Under optimum conditions, the specimen will be mounted centrally. Security gripped along the full width to prevent slipping. The load is applied uniformly across the full specimen width. If a test specimen breaks within 0.25 inch of the line of contact of either of pairs of jaws at a load substantial less than the average of normal breaks, the results shall be recorded [5].

\subsection{Testing Procedure of Tearing Resistance (ASTM D1424)}

Tearing resistance is one of the important properties of a textile fabric. The tear strength of a fabric indicates its resistance to tearing force. For Elmendorf tear resistance testing, at first we took specimen $100 \mathrm{~mm} \times 75 \mathrm{~mm}$. The template was placed on the specimen and cut according to the template. A slit was created at the middle point at the specimen which range was $20 \mathrm{~mm}$. In the test the Elmendorf continuous to tear the fabric from the end of the slit to the opposite edge a distance of $43 \mathrm{~mm}$. Pendulum lever mechanism was used here [6].

\subsection{Testing Procedure of Color Fastness to Rubbing (ISO 105-X12)}

Rubbing fastness is the resistance to fading of dyed textiles when rubbed against a rough surface. This test determines the fastness of dyestuff to either wet or dry rubbing. For rubbing fastness testing (Figure 3) test specimen $15 \mathrm{~cm} \times 5 \mathrm{~cm}$ was placed on the base of the crock meter. Square of white test cloth $(5 \mathrm{~cm} \times 5 \mathrm{~cm})$ of cotton desized, bleached but without finish was attached to the finger of the crock meter. This finger was used in rubbing action on the sample specimen i.e. rubbing $10 \mathrm{~cm}$ long to and fro 10 times at 10 seconds. 20 rubs in $10 \mathrm{~s}$ and finger pressure on the specimen was $9 \mathrm{~N}$. For testing dry and wet rubbing separate specimen was used. Three specimens for dry rubbing and three specimens for wet 


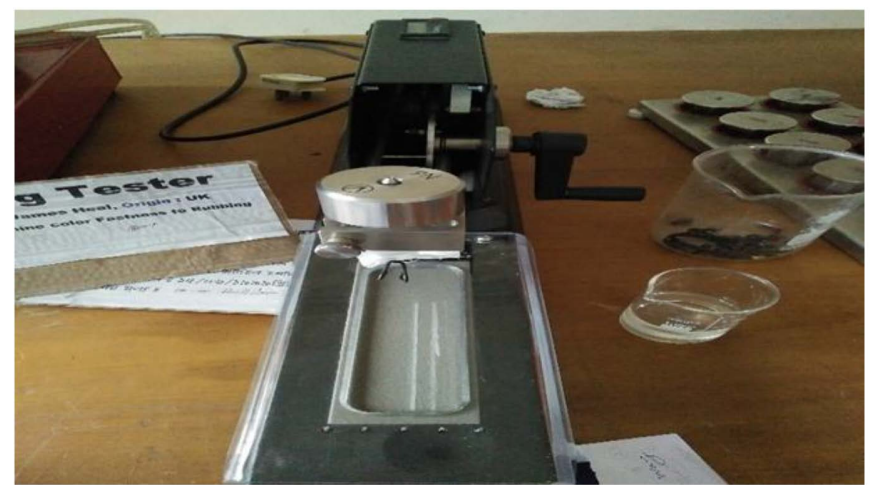

Figure 3. Testing procedure of color fastness to rubbing.

rubbing for warp direction similarly three for dry and three for wet rubbing for weft direction for both fabric. Change in color in the specimen and staining in the white cloth was determined by grey scale [7].

The specification of the crock meter was Brand: James Heal; Origin: UK; Model: 670HD Crock Meter; Volts: N/A; Phase: N/A; Amps: N/A; Frequency: N/A; S/N: $670 / 15 / 1431$

\subsection{Testing Procedure of Pilling Formation (ISO 12945-1)}

For this test four specimens each 5 inch $\times 5$ inch were cut from the fabric. A seam allowance of $12 \mathrm{~mm}$ was marked on the back of each square. In two of the samples the seam was marked parallel to the warp direction and in the other two parallel to the weft direction. The samples were then folded face to face and a seam was sewn on the marked line. This gave two specimens with the seam parallel to the warp and two with the seam parallel to the weft. Each specimen was turned inside out and $6 \mathrm{~mm}$ cut off each end of it thus removing any sewing distortion. The fabric tubes made were then mounted on rubber tubes so that the length of tube showing at each end was the same. Each of the loose ends was taped with poly (vinyl chloride) (PVC) tape so that $6 \mathrm{~mm}$ of the rubber tube was left exposed. All four specimens were then placed in one pilling box. The samples were then tumbled together in a cork-lined box as. The usual number of revolutions used in the test was 18,000 which take $5 \mathrm{hrs}$ [8].

The specification of the machine was Brand: James Heal; Origin: UK; Model: 1516 ORBITOR; Volts: 110-230 V; Frequency: 50/60 Hz; Amp: $0.5 \mathrm{~A}$; S/N: $1516 / 2 / 1014$.

\subsection{Testing Procedure of Crease Recovery (ISO 2313)}

A specimen was cut from the fabrics with a template 2 inch long by 1 inch wide. It was carefully creased by folding in half placing it between two glass plates and adding a $2 \mathrm{~kg}$ weight.

After $1 \mathrm{~min}$ the weight was removed and the specimen transferred to the fabrics clamp on the instrument and allowed to recover from crease. As it recovers, the dial shown in Figure 4 of the instrument was rotated to keep the free 


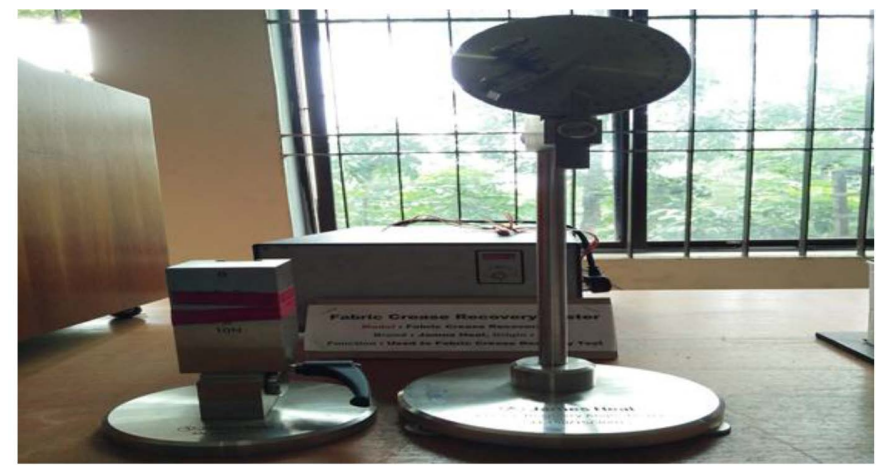

Figure 4. Crease recovery testing process.

edge of the specimen in line with the knife edge. At the end of the time period allowed for recovery, usually $1 \mathrm{~min}$ the recovery angle in degrees was read on the engraved scale. Warp and weft way recovery were reported separately to the nearest degree from the mean values of ten tests in each direction [9].

\subsection{Testing Procedure of Drape Ability Test (BS EN 9073, BS 5058, ERT 90-1)}

Drape is the property of fabric which indicates the ability of a fabric to assume a graceful appearance in use. It is the opposite characteristically feature of stiffness of the fabric. In this testing process a circular specimen about 10 inch in diameter was supported on a circular disk (see Figure 5) about 5 inch diameter and the unsupported area drape over the edge. The fabric will assume some folded configuration and the shape of the project area will not be circular. The drape was then measured in terms of drape co-efficient F considering areas. Drape co-efficient is the ratio of projected area of the draped specimen to its undraped of the area of the supporting disk. Thus, $\mathrm{F}=(\mathrm{As}-\mathrm{Ad}) /(\mathrm{AD}-\mathrm{Ad})$, where $\mathrm{AD}$ is the area of the specimen, Ad is the area of the supporting disk and As is the actual projected area of the specimen [10].

The specification of the machine is Model: Drape Tester; Brand: James Heal; Origin: UK.

\subsection{Testing Procedure of Color Fastness to Wash (ISO 105 C04)}

Fastness to washing is one of the important dyeing properties to the customer. For testing washing fastness cut out a specimen of $10 \mathrm{~cm} \times 4 \mathrm{~cm}$ and make sure all colors were included (if necessary use additional specimen) in it, sewing it along all four edges with the same size of multi-fibre fabric (Figure 6). This was the composite test specimen. The composite specimen was tested in a wash wheel or an equivalent apparatus at $95^{\circ} \mathrm{C} \pm 20^{\circ} \mathrm{C}$ for 30 minutes using the ECE color fastness test detergent 77 (ISO std. Soap) $5 \mathrm{~g} / 1$ and $2 \mathrm{~g} / 1$ soda ash with 10 steel balls to give a liquor ratio of 50:1 [11].

\subsection{Testing Procedure of Color Strength}

The color intensities of $100 \%$ cotton $2 / 1 \mathrm{~S}$ twill and $3 / 1 \mathrm{~S}$ twill woven fabrics are 


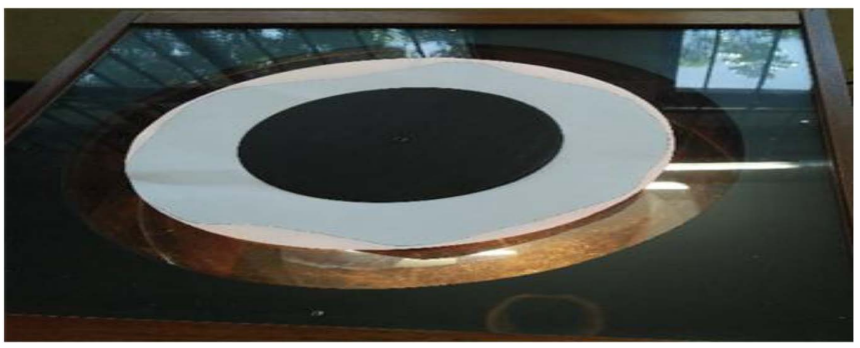

Figure 5. Fabric drape co-efficient testing process.

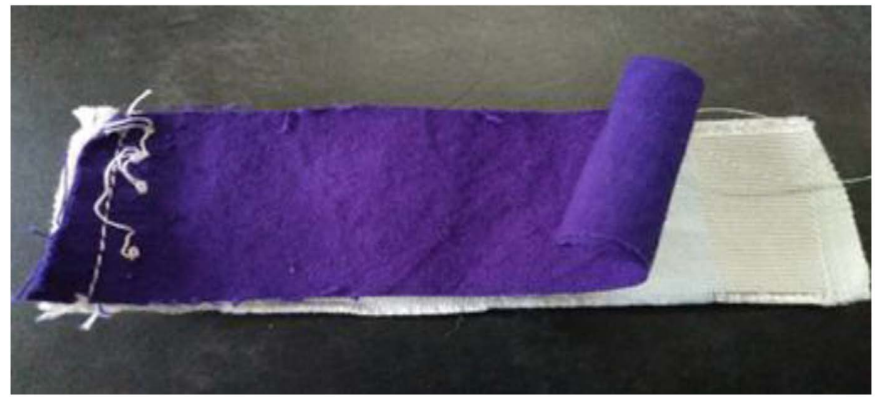

Figure 6. Color staining to multi fiber fabric.

measured and compared by using a UV VIS-NIR reflective spectrometer (Spectra Flash SF $600 \mathrm{X}, \mathrm{USA}$ ), over the range of $360 \mathrm{~nm}$ to $700 \mathrm{~nm}$ [12].

\section{Results and Discussion}

\subsection{Determination of Tensile Strength}

The results show that the warp-wise tensile strength (Table 1 ) of $2 / 1$ twill woven fabric is more than the warp-wise tensile strength of $3 / 1$ twill woven fabric. And also weft-wise tensile strength (Table 2) of $2 / 1$ twill woven is more than the weft-wise tensile strength of 3/1 twill woven fabric. The tensile strength of a fabric varies with: 1) EPI variation; 2) PPI variation; 3) Count variation and also depends on the construction of the fabric.

\subsection{Determination of Tearing Strength}

Tear strength is the resistance of the fabric against tearing or force required to propagate the tear once it is initiated. After completing test the following results are found.

From Figure 7 it is seen that tearing Strength test for Twill 2/1 (warp Way) are $1.191 \mathrm{lbf}$ and $1.256 \mathrm{lbf}$ whereas $3 / 1$ twill (Warp Way) are $1.388 \mathrm{lbf}$ and 1.519 lbf-2/1 twill has lower strength than 3/1 twill due to lose constructions and fewer interlacing, where the yarns can easily move and bunch together, $3 / 1$ twill weave shows higher resistance to the applied force than $2 / 1$ Twill weave.

\subsection{Determination of Color Fastness to Rubbing}

A fastness is a place, such as a castle, which is considered safe because it is difficult to reach or easy to defend against attack. This test is designed to determine 
Table 1 . Tensile strength of $2 / 1 \& 3 / 1$ twill woven fabrics in warp way.

\begin{tabular}{ccccc}
\hline Fabric structure & Sample & Sample & Sample & Average \\
\hline $2 / 1$ Twill & 1 & 2 & 3 & $530.14 \mathrm{~N}$ \\
$3 / 1$ Twill & $530.09 \mathrm{~N}$ & $529.85 \mathrm{~N}$ & $530.48 \mathrm{~N}$ & $525.72 \mathrm{~N}$ \\
\hline
\end{tabular}

Table 2. Tensile strength of $2 / 1 \& 3 / 1$ twill woven fabrics in weft way.

\begin{tabular}{ccccc}
\hline Fabric structure & Sample & Sample & Sample & Average \\
\hline $2 / 1$ Twill & 1 & 2 & 3 & $340.97 \mathrm{~N}$ \\
$3 / 1$ Twill & $340.52 \mathrm{~N}$ & $341.02 \mathrm{~N}$ & $341.37 \mathrm{~N}$ & $337.43 \mathrm{~N}$ \\
\hline
\end{tabular}

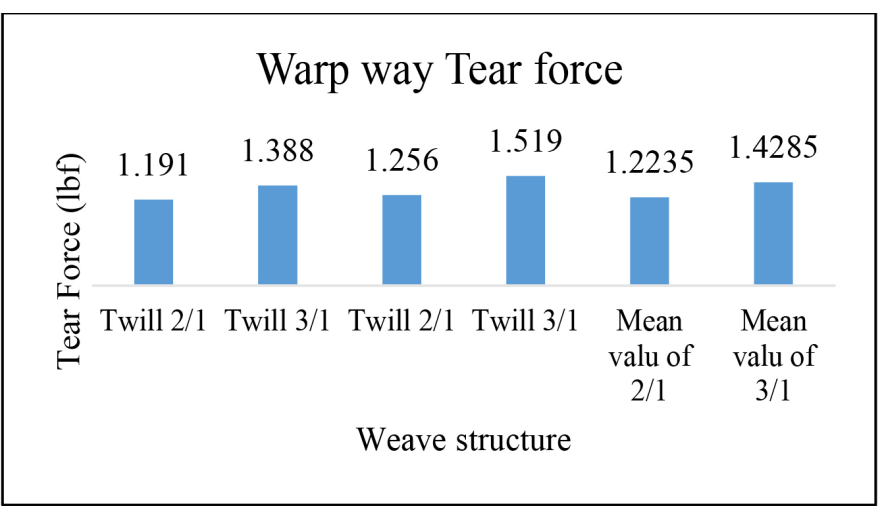

(a)

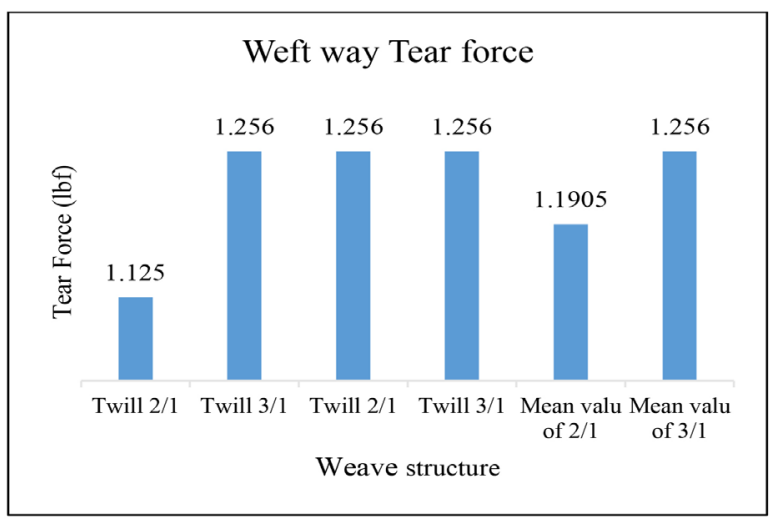

(b)

Figure 7. Show the comparative analysis of tearing strength. (a) Warp way tear force; (b) Weft way tear force.

the degree of color which may be transferred from the surface of a colored fabric to a specify test cloth for rubbing (which could be dry and wet).

After testing color fastness to rubbing we have found the following results:

Dry rubbing fastness results (Figure 8) of 3/1 twill and 2/1 twill in both warp direction and weft direction are same (Figure 8(a) and Figure 8(b)) and wet rubbing fastness (Figure 9) results of $2 / 1$ twill and 3/1 twill in both warp and weft direction are slightly changed. From Figure 9(a) \& Figure 9(b), it is found that wet rubbing for $3 / 1$ twill in both warp and weft direction fair and moderate respectively. But it for $2 / 1$ twill are good to moderate fair respectively.

\subsection{Pilling Resistance Test of Woven Fabric}

Pilling is a fabric surface fault characterized by little pills of entangled fiber clinging to the cloth surface \& giving the garments an unsightly appearance.

It is seen from Figure 10 that pill rating for both samples $(2 / 1$ twill $\& 3 / 1)$ are same. Their moderate pilling behavior due to less interlacement of the weaves the migratory tendency of the fibers is comparatively high. As a result, it is found that $2 / 1$ twill fabric and $3 / 1$ twill fabric is same resistance to pill formation. 


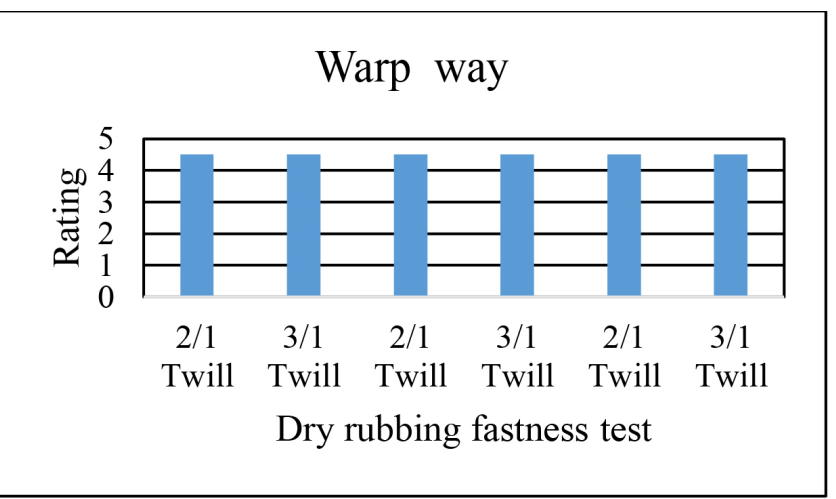

(a)

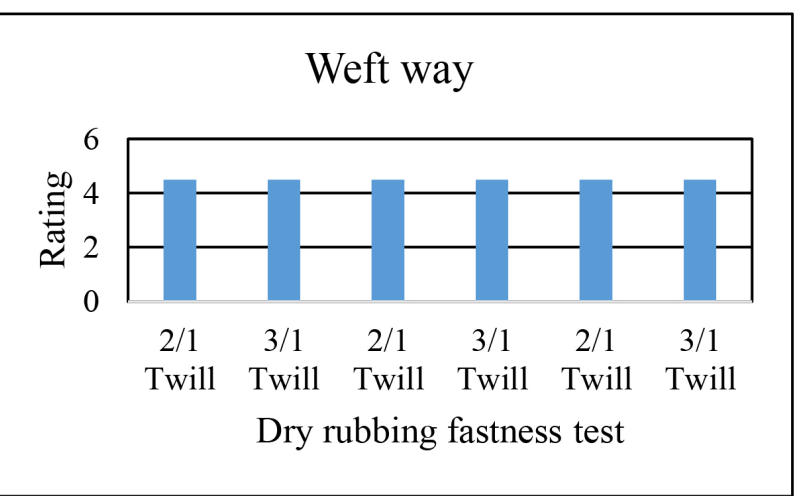

(b)

Figure 8. Show the comparative analysis of dry rubbing fastness test in (a) warp and (b) weft way of twill woven fabric. (a) Warp way dry rubbing fastness test; (b) Weft way dry rubbing fastness test.

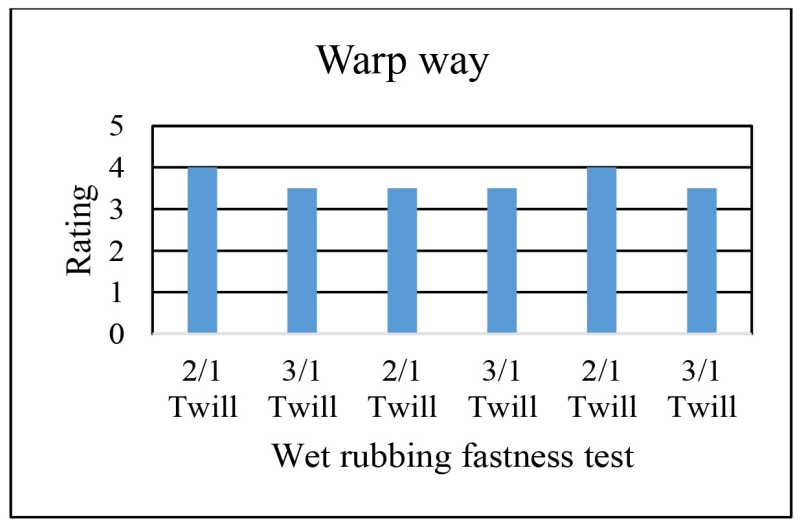

(a)

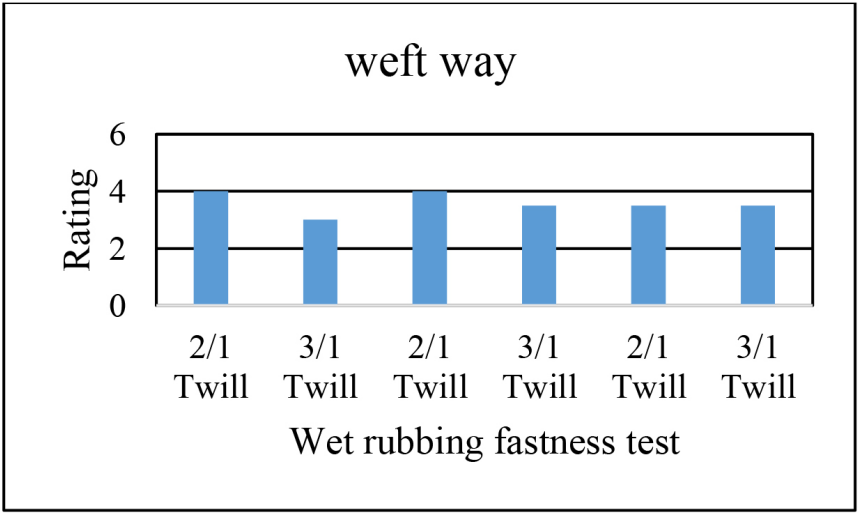

(b)

Figure 9. Show the comparative analysis of wet rubbing fastness test in (a) warp and (b) weft way of twill woven fabrics. (a) Warp way wet rubbing fastness test; (b) Weft way wet rubbing fastness test.

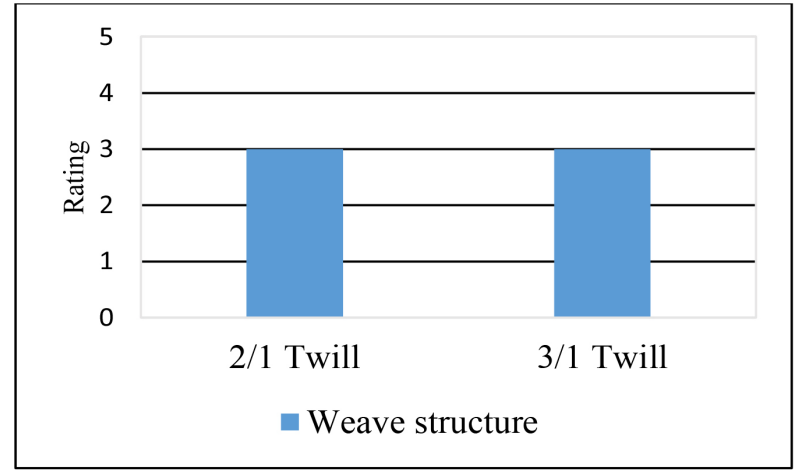

Figure 10. Show the Comparative analysis of pilling.

\subsection{Recovery Angle Test of Woven Fabric}

Crease recovery is determined depending upon the recovery angle. If the angle is $0^{\circ}$ then recovery is zero and if the angle is $180^{\circ}$ then recovery is full.

Here the recovery angle (shown in Figure 11 ) for the $3 / 1$ twill woven fabric in warp way is $105.2^{\circ}$ and in weft way is $79.6^{\circ}$ (from Table 3 ). The recovery angle 


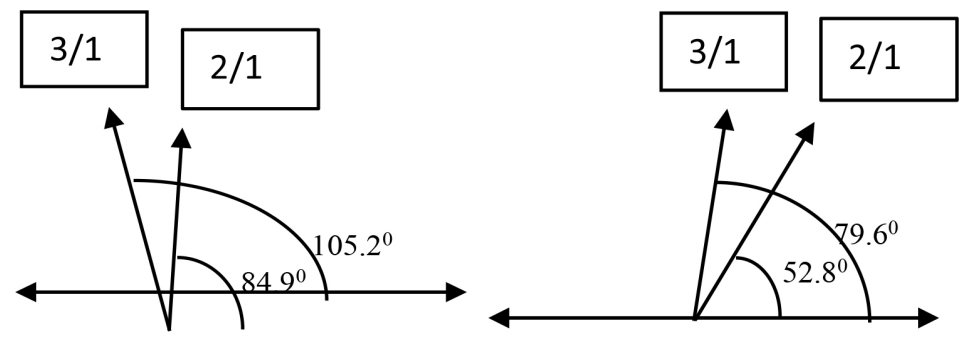

(a) Warp way

(b) Weft way

Figure 11. Show the comparative analysis of crease recovery angle in (a) warp way and (b) weft way of Twill woven fabric.

Table 3. Recovery angle of 3/1 twill woven fabric is obtained from test.

\begin{tabular}{|c|c|c|c|c|}
\hline \multirow{2}{*}{ Sample No. } & \multicolumn{2}{|c|}{ Warp way } & \multicolumn{2}{|c|}{ Weft way } \\
\hline & Recovery angle & Average & Recovery angle & Average \\
\hline 1 & $106^{\circ}$ & \multirow{9}{*}{$105.2^{\circ}$} & $81^{\circ}$ & \multirow{10}{*}{$79.6^{\circ}$} \\
\hline 2 & $105^{\circ}$ & & $70^{\circ}$ & \\
\hline 3 & $107^{\circ}$ & & $76^{\circ}$ & \\
\hline 4 & $119^{\circ}$ & & $95^{\circ}$ & \\
\hline 5 & $115^{\circ}$ & & $85^{\circ}$ & \\
\hline 6 & $96^{\circ}$ & & $78^{\circ}$ & \\
\hline 7 & $94^{\circ}$ & & $93^{\circ}$ & \\
\hline 8 & $109^{\circ}$ & & $66^{\circ}$ & \\
\hline 9 & $106^{\circ}$ & & $88^{\circ}$ & \\
\hline 10 & $95^{\circ}$ & & $64^{\circ}$ & \\
\hline
\end{tabular}

for $2 / 1$ twill woven fabric in warp way is $84.9^{\circ}$ and in weft way is $52.8^{\circ}$ (from Table 4).

As warp yarn is characterized by various treatments such as sizing, so it achieved higher tensile strength than weft yarn. For this reason its recovery behavior is better than weft yarn.

The crease recovery of $3 / 1$ and $2 / 1$ twill fabrics in warp way is greater than the weft way. Because with the increase in the yarn linear density, yarn becomes coarser. For this reason the number of the fibers in the cross-section increases and correspondingly elasticity decrease and the crease recovery becomes harder.

\subsection{Determination of Drape Co-Efficiency}

The draping quality of fabric is affected by the stiffness of the Fabric. Here, Drape Co-efficiency of $3 / 1$ twill is greater than $2 / 1$ twill (see Table 5) because of the $3 / 1$ twill less interlacement than $2 / 1$ twill.

\subsection{Determination of Color Fastness to Wash}

The results show (Figure 12) that color staining on Acetate, Cotton, Acrylic and Wool fiber for $2 / 1$ twill is higher than $3 / 1$ twill fabric (Figure 12). And Color staining on Polyester for $2 / 1$ twill is lower than $3 / 1$ twill fabric. 
Table 4. Recovery angle of $2 / 1$ twill woven fabric is obtained from test.

\begin{tabular}{|c|c|c|c|c|}
\hline \multirow{2}{*}{ Sample No } & \multicolumn{2}{|c|}{ Warp way } & \multicolumn{2}{|c|}{ Weft way } \\
\hline & Recovery angle & Average & Recovery angle & Average \\
\hline 1 & $69^{\circ}$ & & $53^{\circ}$ & \\
\hline 2 & $89^{\circ}$ & & $41^{\circ}$ & \\
\hline 3 & $84^{\circ}$ & & $36^{\circ}$ & \\
\hline 4 & $92^{\circ}$ & & $49^{\circ}$ & \\
\hline 5 & $85^{\circ}$ & & $50^{\circ}$ & \\
\hline 6 & $82^{\circ}$ & $84.9^{\circ}$ & $41^{\circ}$ & $52.8^{\circ}$ \\
\hline 7 & $83^{\circ}$ & & $69^{\circ}$ & \\
\hline 8 & $84^{\circ}$ & & $61^{\circ}$ & \\
\hline 9 & $88^{\circ}$ & & $66^{\circ}$ & \\
\hline 10 & $93^{\circ}$ & & $62^{\circ}$ & \\
\hline
\end{tabular}

Table 5. Drape Co-efficiency of $2 / 1 \& 3 / 1$ twill woven fabric.

\begin{tabular}{cccccc}
\hline Fabric & SL & $\begin{array}{c}\text { Total weight of the } \\
\text { paper ring(gm) }\end{array}$ & $\begin{array}{c}\text { Weight of the } \\
\text { shaded area(gm) }\end{array}$ & Drape co-efficiency & Mean Drape co-effiency \\
\hline & 1 & 446 & 335 & $(335 \div 446) \times 100=75.11 \%$ & \\
$2 / 1$ Twill & 2 & 446 & 336 & $(336 \div 446) \times 100=75.34 \%$ & $(75.11 \%+75.34 \%+75.11 \%) \div 3=75.19 \%$ \\
& 3 & 446 & 335 & $(335 \div 446) \times 100=75.11 \%$ & \\
\hline $3 / 1$ Twill & 1 & 446 & 339 & $(339 \div 446) \times 100=76 \%$ & \\
& 2 & 446 & 338 & $(338 \div 446) \times 100=75.74 \%$ & $(76 \%+75.74 \%+76 \%) \div 3=75.91 \%$ \\
& 3 & 346 & $(339 \div 446) \times 100=76 \%$ & \\
\hline
\end{tabular}

\subsection{Results of Color Measurement}

Color strength of samples (Figure 13) 2/1 Twill \& 3/1 Twill woven fabrics are measured through $\mathrm{K} / \mathrm{S}$ value. When reflectance is more, absorbance is more, indicates the more $\mathrm{K} / \mathrm{S}$ value. $\mathrm{K} / \mathrm{S}$ value was measured in $360-700 \mathrm{~nm}$ wave length. For $2 / 1$ Twill woven fabric value of $\mathrm{K} / \mathrm{S}$ is 3.616 at $360 \mathrm{~nm}$ and 0.483 at $700 \mathrm{~nm}$. For 3/1 Twill woven fabric value of K/S is 3.635 at $360 \mathrm{~nm}$ and 0.492 at $700 \mathrm{~nm}$ wave length.

\section{Conclusion}

From this project work, we have obtained vest information of physico-chemical properties of twill (2/1 S twill and 3/1 S twill) woven fabrics by analysis their properties. A clear idea about the effects of physico-chemical properties of twill structures of woven fabrics can lead to making further improvement of the twill woven fabrics that will help to many end by using applications especially protective clothing, performs of composite as well as apparels. In the current work, Influenced of Different Twill Geometry in Woven Fabrics. Analysis of Physico-Chemical Properties is studied. It should be noted that even though the 


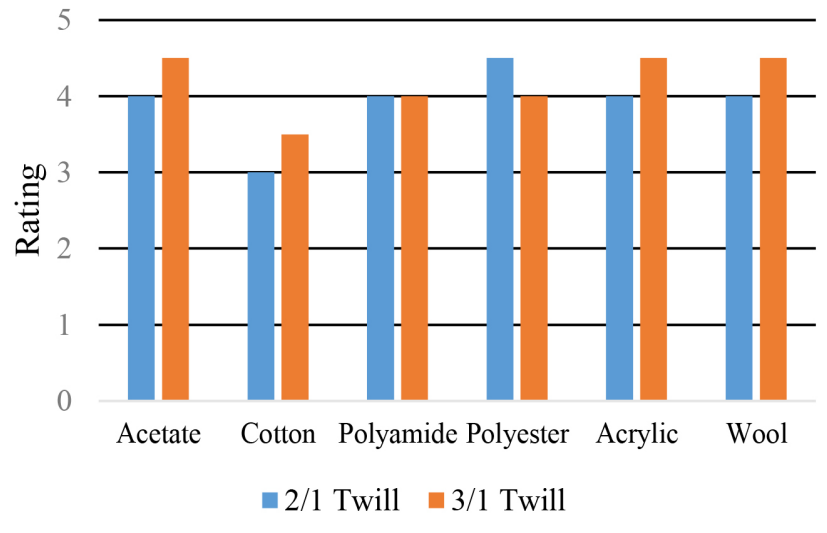

Figure 12. Show the comparative analysis of Color staining on $2 / 1 \&$ 3/1 Twill woven fabric.

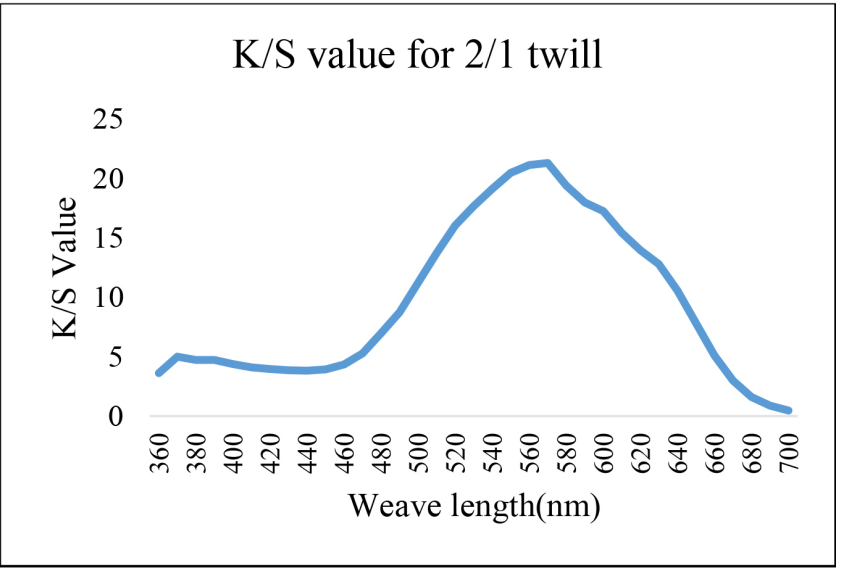

(a)

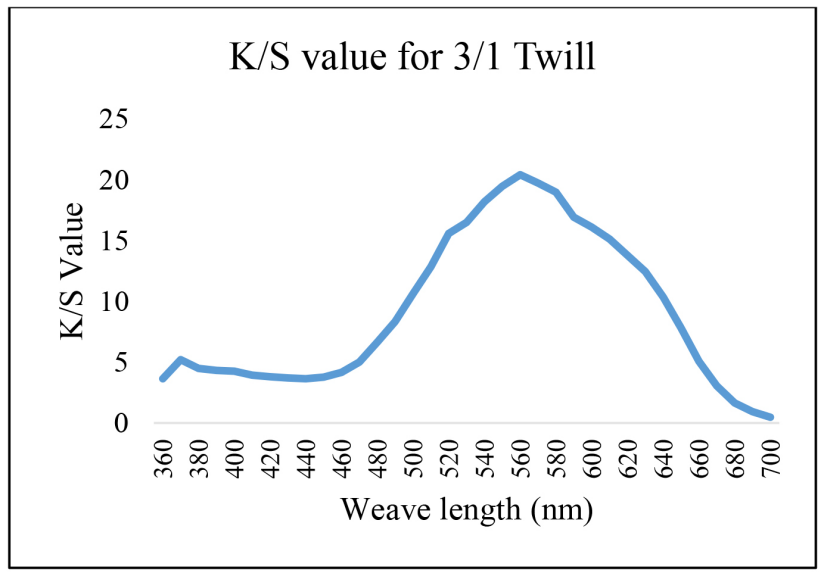

(b)

Figure 13. Show the comparative analysis of K/S value between $2 / 1$ twill (a) \& $3 / 1$ twill (b).

fabrics parameter remains the same, more complex fabric can be implemented and studied as well. Further research work can be done on this research for the enrichment of the depth.

\section{Conflicts of Interest}

The authors declare no conflicts of interest regarding the publication of this paper.

\section{References}

[1] Amin, R. and Haque, M. (2011) Effect of Weave Structure on Fabric Properties. Annals of the University of Oradea, Fascicle of Textiles, Leatherwork, 12, 161-165.

[2] Jahan, I. (2017) Effect of Fabric Structure on the Mechanical Properties of Woven Fabrics. Advance Research in Textile Engineering, 2, 1018. https://doi.org/10.26420/advrestexteng.2017.1018

[3] Woven Fabric Sector of Bangladesh-Opportunities, Challenges and Techniques. 
https://www.textiletoday.com.bd/woven-fabric-sector-bangladesh-opportunities-ch allenges-techniques/

[4] Moody, V. and Needles, H.L. (2004) Tufted Carpet: Textile Fibers, Dyes, Finishes and Processes. William Andrew, Norwich.

[5] ISO 13934-1 (1999) Textiles-Tensile Properties of Fabrics-Part 1: Determination of Maximum Force and Elongation at Maximum Force Using the Strip Method.

[6] Cheng, S.Y., Yuen, C.W., Kan, C.W., Cheuk, K.K.L., Daoud, W.A., Lam, P.L. and Tsoi, W.Y.I. (2010) Influence of Atmospheric Pressure Plasma Treatment on Various Fibrous Materials: Performance Properties and Surface Adhesion Analysis. Vacuum, 84, 1466-1470. https://doi.org/10.1016/j.vacuum.2010.01.012

[7] Kamel, M.M., El-Shishtawy, R.M., Yussef, B.M. and Mashaly, H. (2005) Ultrasonic Assisted Dyeing: III. Dyeing of Wool with Lac as a Natural Dye. Dyes and Pigments, 65, 103-110. https://doi.org/10.1016/j.dyepig.2004.06.003

[8] Periyasamy, A.P. (2012) Effect of Alkali Pretreatment and Dyeing on Fibrillation Properties of Lyocell Fiber. Proceedings of the RMUTP International Conference: Textiles \& Fashion, Bangkok, 3-4 July 2012, 1-11.

[9] Leeder, J.D., Rippon, J.A., Roche, P.H. and Taylor, D.S. (1981) Standard Crease-Recovery Tests for Textiles: Non-Standard Results Caused by Pre-Test Procedures. Journal of the Textile Institute, 72, 42-44. https://doi.org/10.1080/00405008108631583

[10] Fan, J. (2008) Measuring and Predicting Fabric and Garment Drape. In: Fairhurst, C., Ed., Advances in Apparel Production, Elsevier Inc., Amsterdam, 7-25. https://doi.org/10.1533/9781845694463.1.7

[11] Xie, K. and Hou, A. (2004) One-Bath Dyeing of Wool/Acrylic Blends with Reactive Cationic Dyes Based on Monofluorotriazine. Coloration Technology, 120, 307-310. https://doi.org/10.1111/j.1478-4408.2004.tb00235.x

[12] Solaiman, J.S. (2015) Comparative Analysis of Manual Fading and Laser Fading Process on Denim Fabric. Science Discovery, 3, 44-49. https://doi.org/10.11648/j.sd.20150306.11 